\title{
SISTEM PENDUKUNG KEPUTUSAN PEMILIHAN JURUSAN DI SEKOLAH MENENGAH KEJURUAN 1 CENGKARENG JAKARTA
}

\author{
Asri Wahyuni, M.Kom \\ STMIK Nusa Mandiri Jakarta, Program Studi Sistem Informasi \\ Email : asriwahyuni1101@gmail.com
}

\begin{abstract}
Abstrak
Sistem pendukung keputusan adalah sistem komputerisasi yang dirancang untuk meningkatkan efektifitas pengambilan keputusan untuk memecahkan masalah yang bersifat semi terstruktur dan terstruktur sehingga dalam proses pengambilan keputusan bisa lebih berkualitas.

Keputusan memilih jurusan di sekolah harus akurat. Penjurusan pada siswa Sekolah Menengah Kejuruan (SMK) 1 jurusan Cengkareng Jakarta dilakukan pada saat penerimaan siswa baru. Siswa akan memutuskan apa jurusan yang dipilih, masalah yang umum adalah kesulitan dalam proses penempatan siswa dalam memilih jurusan yang masih belum yakin akan siswa pilih jurusan yang akhirnya bubar karena jurusan tidak sesuai dengan kemampuannya. Desain Sistem Pendukung Keputusan dibangun menggunakan PHP dan MySQL serta software Adobe Dreamweaver CS6. Dengan menggunakan software tersebut maka pengerjaan website akan lebih cepat dan mudah. Adapun tabel yang dipakai dalam pembuatan web ini adalah tabel siswa, tabel jurusan, tabel konsultasi jurusan, tabel user, tabel pendapat, tabel akademik, tabel nilai rapor, dan tabel info. Semua tabel tersebut digunakan untuk menampung data yang diperlukan dalam membangun website.
\end{abstract}

\begin{abstract}
Decision support system is a computerized system designed to improve the effectiveness of decision-making to solve problems that are semi-structured and structured so that in the decisionmaking process can be more qualified.

The decision to choose a course in school should be accurate. Apprenticeship for Vocational High School (SMK) 1 students of Cengkareng Jakarta is conducted at the time of admission of new students. Students will decide what majors are chosen, a common problem is the difficulty in the process of placement of students in choosing majors who are still not sure of the students choose departments that eventually dissolved because the majors are not in accordance with ability. Decision Support System Design is built using PHP and MySQL as well as Adobe Dreamweaver CS6 software. By using the software then the website work will be faster and easier. The tables used in the making of this web are student tables, department tables, consulting tables majors, user tables, opinion tables, academic tables, report card grades, and info tables. All the tables are used to accommodate the data needed in building the website.
\end{abstract}

Key words: Decision Support Systems, selection of majors, PHP, MySQL, Website. 


\section{PENDAHULUAN}

Suhardjo dan Bambang Eka P. (2013:1), "pengembangan bidang informasi dan telekomunikasi mengalami revolusi yang cukup signifikan khususnya untuk perangkat audio, visual, mobile phone dan komputer". Begitu juga dalam penyelenggaraan sekolah kejuruan seperti Sekolah Menengah Kejuruan (SMK) harus benar-benar konsekuen, artinya harus dapat menghasilkan output yang siap untuk menghadapi tantangan dalam dunia kerja. Untuk membuat keputusan harus benarbenar mempertimbangkan pilihan-pilihan yang sesuai dengan kemampuan untuk dapat menentukan jurusan sehingga proses ini membutuhkan sebuah sistem penunjang keputusan.

Sistem penunjang keputusan merupakan suatu sistem terkomputerisasi yang dirancang untuk meningkatkan efektivitas dalam pengambilan keputusan untuk memecahkan masalah yang bersifat semi terstruktur dan tidak terstruktur sehingga dalam proses pengambilan keputusan yang dilakukan dapat lebih berkualitas.

Pengambilan keputusan untuk memilih minat jurusan dalam suatu sekolah harus akurat, begitu juga di Sekolah Menengah Kejuruan (SMK) 1 Cengkareng Jakarta untuk penjurusan dilakukan pada saat siswa naik ke kelas XI (sebelas). Setelah wali kelas menerima seluruh nilai di akhir semester maka wali kelas akan memutuskan apakah siswa tersebut naik kelas atau tidak. Jika siswa tersebut dinyatakan naik kelas oleh wali kelas maka akan dilakukan proses penjurusan. Permasalahan yang biasa terjadi saat proses penjurusan yaitu sulitnya dalam proses mekanisme penilaian yang masih menggunakan sistem manual.

Berdasarkan penelitian sebelumnya "Banyak siswa kelas X semester 2 bingung untuk memilih jurusan apa yang akan mereka pilih untuk naik di kelas XI, minat bakat dan nilai akademik siswapun kadang kala tidak sejalan. Gurupun belum bisa mengukur kemampuan siswa dari segi bakat dan akademik. Kadang kala guru hanya mengukur dari segi nilai rapor atau ranking di kelas" (Fitriyani 2012:1).

Pengambilan keputusan dapat diketahui secara akurat atau tidak akurat, melalui beberapa penilaian yang dilakukan berdasarkan pada kemampuan siswa di dalam menjawab soal-soal mata pelajaran tertentu yang diberikan pada saat kenaikan kelas XI (sebelas). Sehingga dari penilaian-penilaian mata pelajaran tersebut pihak sekolah dapat mengambil keputusan untuk penentuan jurusan bagi siswa-siswinya.

\section{TINJAUAN PUSTAKA}

\section{Internet}

Menurut Darma dkk (2009:1), “internet adalah rangkaian komputer yang terhubung satu sama lain". Internet merupakan sistem komputer umum, yang berhubung secara global dan menggunakan TCP/IP sebagai protokol pertukaran paket (packet switching communication protocol). Cara menghubungkan rangkaian dengan kaedah ini dinamakan internetworking atau dengan kata lain, definisi internet adalah jaringan besar yang saling berhubungan dari jaringanjaringan komputer yang menghubungkan orang-orang dan komputer-komputer diseluruh dunia, melalui telepon, satelit dan sistemsistem komunikasi yang lain. Internet dibentuk oleh jutaan komputer yang terhubung bersama dari seluruh dunia, memberi jalan bagi informasi (mulai dari teks, gambar, audio, video, dan lainnya) untuk dapat dikirim dan dinikmati bersama. Untuk dapat bertukar informasi, digunakan protocol standar yaitu Transmision Control Protocol dan internet Protocol yang lebih dikenal sebagai TCP/IP. TCP (Transmission Control Protocol) bertugas untuk memastikan bahwa semua hubungan bekerja dengan benar, sedangkan IP (Internet Protocol) yang mentransmisikan data dari satu komputer ke komputer lain. TPC/IP secara umum berfungsi memilih rute terbaik transmisi data, memilih rute alternatif jika suatu rute tidak dapat di gunakan, mengatur dan mengirimkan paket-paket pengiriman data. 


\section{PHP (Personal Home Page)}

Menurut Gunawan (2010:12), "PHP (Hypertext Preprocessor/Personal Home Page) adalah bahasa pemrograman yang memungkinkan para web developer untuk membuat aplikasi web yang dinamis dengan cepat dan mudah". Bahasa pemrograman PHP diciptakan oleh Rasmus Lerdorf pada tahun 1995 yang berfungsi untuk membuat website dinamis maupun aplikasi web. Sebagian besar sintaks mirip dengan bahasa C, Java, Asp dan Perl, ditambah beberapa fungsi PHP yang spesifik. PHP adalah bahasa HTML-embedded scripting web. Hal ini berarti kode PHP dapat disisipkan ke dalam HTML halaman Web. Berbeda dengan HTML yang hanya bisa menampilkan konten statis, PHP bisa berinteraksi dengan database, file dan folder, sehingga membuat PHP bisa menampilkan konten yang dinamis dari sebuah website. Blog, Toko Online,CMS, Forum, dan Website Social Networkingadalah contoh aplikasi web yang bisa dibuat oleh PHP. PHP adalah bahasa scripting, bukan bahasa tag-based seperti HTML. PHP termasuk bahasa yang crossplatform, ini artinya PHP bisa berjalan pada sistem operasi yang berbeda-beda (Windows, Linux, ataupun Macintosh). Program PHP ditulis dalam fileplain text (teks biasa) dan mempunyai akhiran ".php". PHP memiliki beberapa kelebihan dibanding server sideprogramming lain, yaitu mudah dibuat dan kecepatan prosesnya yang tinggi. Dengan menggunakan PHP maka maintenance suatu situs web menjadi lebih mudah. Proses update data dapat dilakukan dengan menggunakan aplikasi yang dibuat dengan menggunakan script PHP. Fungsi-fungsi yang ada di PHP tidak case sensitive tetapi variabelnya case sensitive (membedakan huruf besar dan kecil).

\section{Sistem Penunjang Keputusan}

Menurut Hermawan (2005:1), "Desicion support system atau sistem penunjang keputusan adalah sebuah sistem yang mampu memberikan kemampuan baik kemampuan pemecahan masalah maupun kemampuan pengkomunikasian untuk masalah semitersruktur". Sistem penunjang keputusan merupakan perpaduan antara keahlian manusia dan juga komputer. Dengan kemampuan yang dimiliki, sistem penunjang keputusan diharapkan dapat membantu dalam pengambilan keputusan baik untuk masalah semi tersrtuktur maupun tidak tersrtukur.

Keuntungan dari penggunaan sistern penunjang keputusan, yaitu :

a. Dapat memperluas kemampuan seorang pengambil keputusan dalam memproses data/informasi bagi pemakainya.

b. Membantu pengambil keputusan dalam hal penghematan waktu yang dibutuhkan untuk memecahkan masalah, terutama berbagai masalah yang sangat kompleks dan tidak terstruktur.

c. Dapat menghasilkan solusi dengan lebih cepat serta hasilnya dapat diandalkan.

d. Dapat menjadi alternatif bagi pengambil keputusan dalam memahami permasalahannya, karena Sistem Penunjang Keputusan (SPK) mampu menyajikan berbagai alternatif.

e. Mampu menyediakan bukti tambahan untuk memberikan pembenaran, sehingga dapat memperkuat posisi pengambil keputusan.

Sistem penunjang keputusan terdiri dari 3 (tiga) komponen utama atau sub sistern, yaitu :

a. Subsistem Data (Data Subsystem)

Komponen Sistem Penunjang Keputusan (SPK) sebagai penyedia data bagi sistern, yang mana data disimpan dalam Database Management System (DBMS), sehingga dapat diambil dan diekstraksi dengan cepat.

b. Subsistem Model (Model Subsystem)

Keunikan dari sistern ini adalah kemampuannya dalam mengintegrasikan data dengan model-model keputusan.

c. Subsistem Dialog (User System Interface) Melalui sistern dialog ini, sistern dapat diartikulasikan dan diimplementasikan, sehingga pengguna atau pemakai dapat berkomunikasi dengan sistern yang dirancang.

Karena Desicion support system (DSS) berhubungan dengan kegiatan pengambilan keputusan, maka kita perlu mengetahui dengan baik bagaimana proses pengambilan keputusan 
dilakukan. Proses pengambilan keputusan melibatkan 4 tahapan, yaitu:

\section{Tahap Intelligence}

Dalam tahap ini pengambil keputusan mempelajari kenyataan yang terjadi sehingga kita mengidentifikasi dan mendefinisikan masalah yang sedang terjadi, biasanya dilakukan analisis berurutan dari sistern ke subsistem pembentuknya. Dari tahap ini didapatkan keluaran berupa dokumen Pernyataan Masalah.

2. Tahap Design

Dalam tahap ini pengambil keputusan menemukan, mengembangkan, dan menganalisis semua pemecahan yang mungkin, yaitu melalui pembuatan model yang mewakili kondisi nyata masalah. Dari tahap ini didapatkan keluaran berupa dokumen Alternatif Solusi.

3. Tahap Choice

Dalam tahap ini pengambil keputusan memilih salah satu alternatif pemecahan yang dibuat pada tahap design yang dipandang sebagai aksi yang paling tepat untuk mengatasi masalah yang sedang dihadapi. Dari tahap ini didapatkan keluaran berupa dokumen Solusi dan Rencana Implementasinya.

4. Tahap Implementation

Dalam tahap ini pengmbil keputusan menjalankan rangkaian aksi pemecahan yang dipilih ditahap choice. Implementasi yang sukses ditandai dengan terjawabnya masalah yang dihadapi, sementara kegagalan ditandai dengan tetap adanya masalah yang sedang dicoba untuk diatasi. Dari tahap ini didapatkan keluaran berupa laporan Pelaksanaan Solusi dan Hasilnya.

\section{Unifield Modelling Language (UML)}

Menurut Sukamto dan Shalahuddin (2011:113), "Unified Modeling Language (UML) adalah salah satu standar bahasa yang banyak digunakan didunia industri untuk mendefinisikan requirement, membuat analisis dan desain, serta menggambarkan arsitektur dalam pemograman berorientasi objek".

UML muncul karena adanya kebutuhan pemodelan visual untuk menspesifikasikan, menggambarkan, membangun, dan dokumantasi dari sistem perangkat lunak.

Unifield Modelling Language (UML) merupakan bahasa visual untuk pemodelan dan komunikasi mengenai sebuah sistem dengan menggunakan diagram dan teks-teks pendukung. Unifield Modelling Language (UML) hanya berfungsi untuk melakukan pemodelan. Jadi penggunaan Unifield Modelling Language (UML) tidak terbatas pada metodologi tertentu, meskipun pada kenyataannya Unifield Modelling Language (UML) paling banyak digunakan pada metodologi berorientasi objek.

Unifield Modelling Language (UML) mendefinisikan notasi dan syntax/semantik. Notasi Unifield Modelling Language (UML) merupakan sekumpulan bentuk khusus untuk menggambarkan berbagai diagram piranti lunak. Setiap bentuk memiliki makna tertentu, dan Unifield Modelling Language (UML) syntax mendefinisikan bagaimana bentukbentuk tersebut dapat dikombinasikan.

Notasi Unifield Modelling Language (UML) terutama diturunkan dari 3 notasi yang telah ada sebelumnya : Grady Booch OOD (Object Oriented Design), Jim Rumbaugh OMT (Object Modeling Technique), dan Ivar Jacobson OOSE (Object Oriented Software Engineering).

\section{Entity Relationship Diagram (ERD)}

Menurut Kadir (2008:20), "Model E-R adalah suatu model yang digunakan untuk menggambarkan data dalam bentuk entitas, atribut dan hubungan antar entitas. Huruf E sendiri menyatakan entitas dan $\mathrm{R}$ menyatakan hubungan (Relationship).

Model ini dinyatakan dalam bentuk diagram, oleh karena itu sering kali disebut dengan Entity Relationship Diagram (ERD). Model entity relationship merupakan suatu penyajian data dengan menggunakan entity dan relationship”.

Komponen-komponen yang terdapat di dalam Entity Relationship Model:

a. Entity

Entity Adalah yang dapat dibedakan dalam dunia nyata dimana informasi yang 
berkaitan dengannya dikumpulkan. Entityset adalah kumpulan entity yang sejenis.

b. Relationship

Relationship adalah hubungan yang terjadi antara satu lebih entity. Relationship tidak mempunyai keberadaan fisik, kecuali yang mewarisi hubungan antara entity tersebut. Relationship set adalah kumpulan relationship yang sejenis.

c. Atribute

Atribut adalah karakteristik dari entity atau relationship yang menyediakan penjelasan detail tentang atau relationship tersebut. Atribute valueadalah suatu data actual atau informasi yang disimpan di suatu attribute di dalam suatu entity atau relationship.

d. Indicator Tipe

1) Indicator Tipe Associative Object

Berfungsi sebagai objek dan suatu relationship.

2) Indicator Tipe Supertipe

Terdiri dari suatu object dan satu subkategori atau lebih yang di hubungkan dengan satu relationship yang tidak bernama.

e. Cardinality Ratio atau Cardinality

Cardinality ratio adalah menjelaskan hubungan batasan jumlah keterhubungan satu entity dengan entity lainnya atau banyaknya entity yang bersesuaian dengan entity yang lain melalui relationship.

f. Participation Constraint

Menjelaskan apakah keberadaan suatu entity tergantung pada hubungannya dengan entity lain.

g. Representasi dari entity set

Entity set direpresentasikan dalam bentuk table dan nama yang unique. Setiap table terdiri dari sejumlah kolom. Masingmasing kolom diberi nama yang unique pula.

\section{Rancangan Algoritma}

Rancangan algoritma ini berisi flowchart

Sistem Penunjang Keputusan Pemilihan Jurusan di Sekolah Menengah Kejuruan (SMK) Cengkareng 1 Jakarta adalah sebagai berikut :

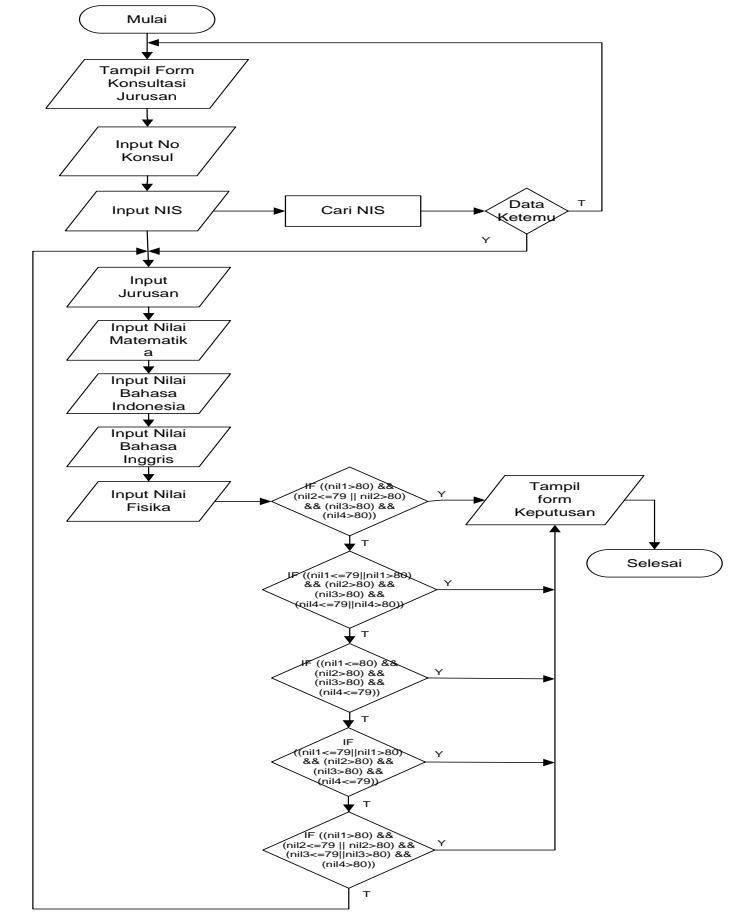

Gambar 1. Flowchart Konsultasi Jurusan

\section{Basis Pengetahuan}

Basis pengetahuan berisi pengetahuan penting untuk pengertian, formulasi dan pemecahan masalah.

Basis pengetahuan memasukkan dua elemen yaitu : fakta (facts) seperti situasi masalah dan teori dari area masalah dan heuristic khusus atau rule-rule yang menghubungkan penggunaan pengetahuan untuk pemecahan masalah spesifik dalam sebuah domain khusus.

Informasi dalam basis pengetahuan tergabung dalam sebuah program komputer oleh proses yang disebut dengan representasi pengetahuan.

\section{Tabel Keputusan}

Tabel keputusan akan disusun kriteria nilai sebagai berikut :

Tabel 1. Tabel Keputusan Pemilihan Jurusan

\begin{tabular}{|c|c|c|c|c|c|c|}
\hline Kode & $\begin{array}{c}\text { Kriteria } \\
\text { Nilai }\end{array}$ & AK & AP & BR & PM & TKJ \\
\hline K1 & MT1 & & $*$ & $*$ & $*$ & \\
\hline K2 & MT2 & $*$ & $*$ & & $*$ & $*$ \\
\hline K3 & BI1 & $*$ & & & & $*$ \\
\hline K4 & BI2 & $*$ & $*$ & $*$ & $*$ & $*$ \\
\hline
\end{tabular}


Tabel 1. Tabel Keputusan Pemilihan Jurusan (lanjutan)

\begin{tabular}{|c|c|c|c|c|c|c|}
\hline Kode & $\begin{array}{c}\text { Kriteria } \\
\text { Nilai }\end{array}$ & AK & AP & BR & PM & TKJ \\
\hline K5 & BN1 & & & & & $*$ \\
\hline K6 & BN2 & $*$ & $*$ & $*$ & $*$ & $*$ \\
\hline K7 & FS1 & & $*$ & & $*$ & \\
\hline K8 & FS2 & $*$ & $*$ & & & $*$ \\
\hline
\end{tabular}

Keterangan :

MT1 = Matematika $<=79$

MT2 = Matematika $>80$

BI1 = Bahasa Indonesia $<=79$

BI2 $=$ Bahasa Indonesia $>80$

$\mathrm{BN} 1=$ Bahasa Inggris $<=79$

$\mathrm{BN} 2=$ Bahasa Inggris $>80$

FS1 $=$ Fisika $<=79$

FS2 $=$ Fisika $>80$

\section{Rule Pemilihan Jurusan}

Rule pemilihan jurusan untuk merepresentasikan pengetahuan digunakan metode kaidah produksi yang biasanya ditulis dalam bentuk Jika-Maka (IF-Then). Faktafakta atau aturan-aturan yang digunakan dalam sistem pakar ini adalah:

\section{Rule 1 :}

IF MT2 and BI1 and $\mathrm{BI} 2$ and $\mathrm{BN} 2$ and $\mathrm{FS} 2$ THEN Akuntansi

Rule 2 :

IF MT1 and MT2 and BI2 and BN2 and FS1 and FS2 THEN Administrasi Perkantoran

Rule 3 :

IF MT1 and BI2 and BN2 THEN Broadcast

Rule 4 :

IF MT1 and MT2 and BI2 and BN2 and FS1

THEN Pemasaran

\section{Rule 5 :}

IF $\mathrm{MT} 2$ and $\mathrm{BI} 1$ and $\mathrm{BI} 2$ and $\mathrm{BN} 1$ and $\mathrm{BN} 2$ and FS2 THEN Teknik Komputer Jaringan

\section{Pohon Keputusan Pemilihan Jurusan}

Fakta-fakta dan aturan dalam rule sistem penunjang keputusan dapat digambarkan dalam pohon keputusan adalah sebagai berikut :

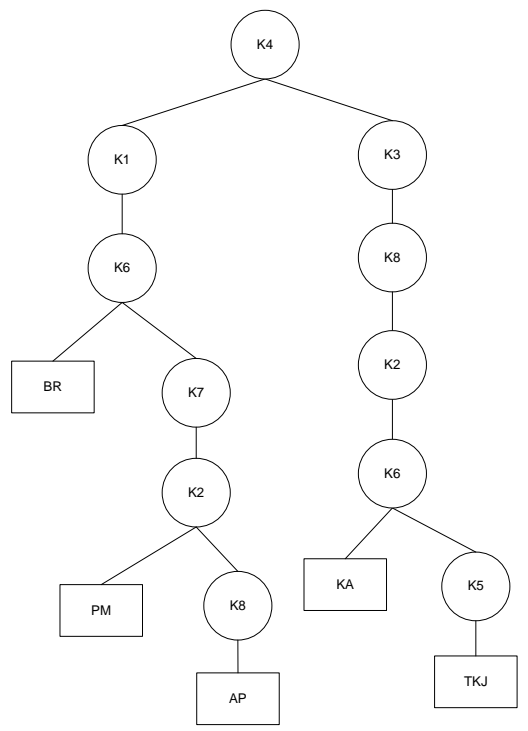

Gambar 2. Pohon Keputusan Pemilihan Jurusan

\section{Desain Database}

Entity Relationship Diagram menjelaskan hubungan antar data dalam basis data yangterdiri dari object-object dasar yang mempunyai hubungan atau relasi antar objekobjek tersebut. Dibawah ini ERD (Entity Relationship Diagram) yang dibuat dalam sistem:

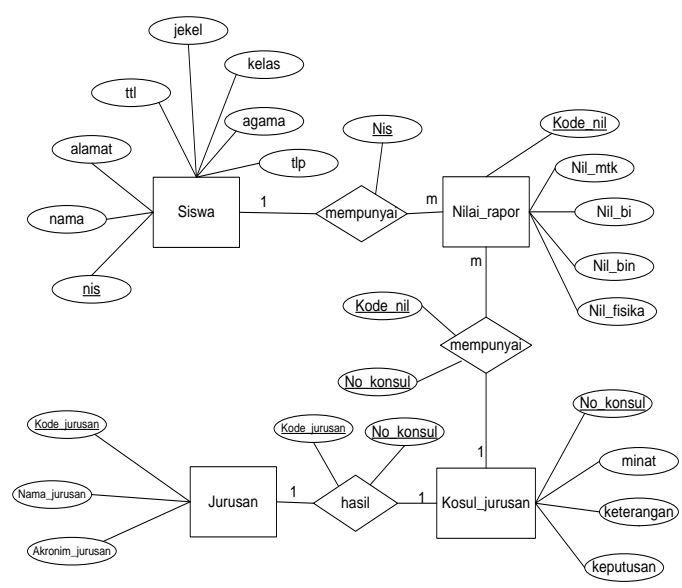

Gambar 3 Entity Relationship Diagram (ERD)

\section{Desain Sistem}

Desain Sistem Penunjang Keputusan Pemilihan Jurusan di SMK Cengkareng 1 
Jakarta dengan 4 UML yaitu Activity Diagram, Use Case Diagram, Sequence Diagram, dan Deployment Diagram antara lain :

\section{Activity Diagram Data Siswa}

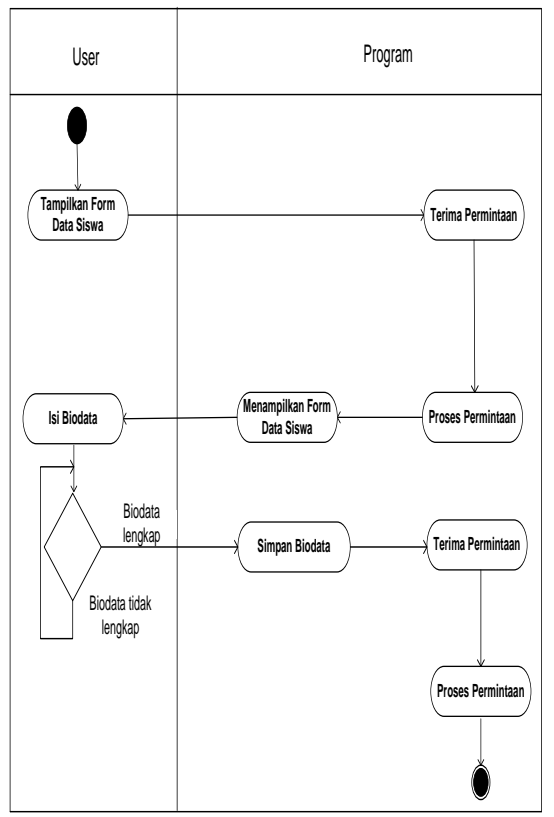

Gambar 4. Activity Diagram Data Siswa

\section{Activity Diagram Konsultasi Jurusan}

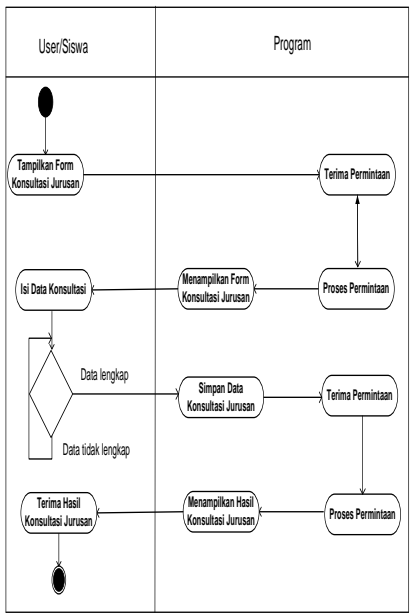

Gambar 5. Activity Diagram Konsultasi Siswa

\section{Activity Diagram Data Jurusan}

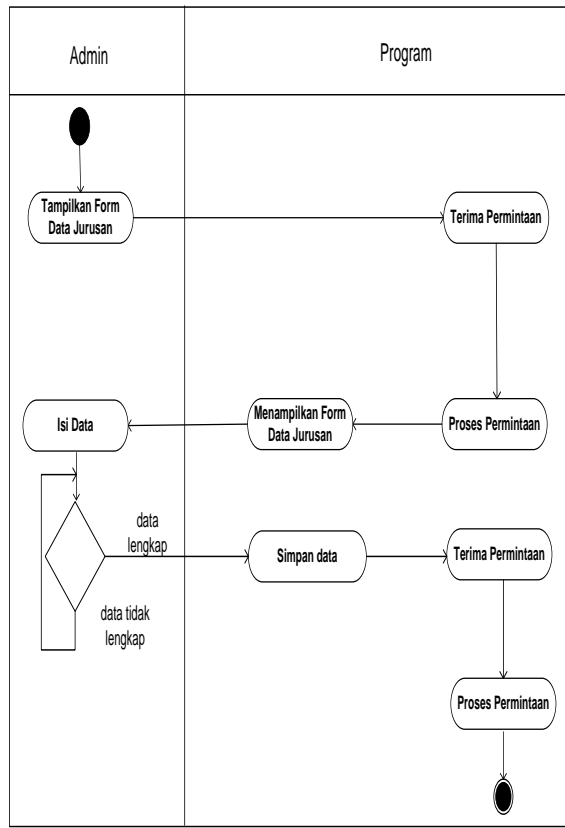

Gambar 6. Activity Diagram Data Jurusan

\section{Use Case Diagram SPK Untuk Pemilihan Jurusan}

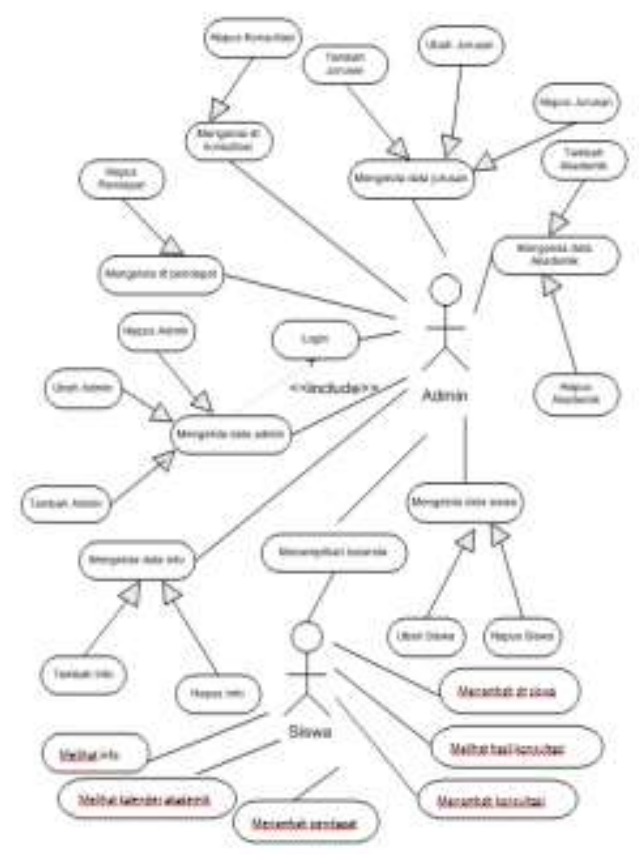

Gambar 7. Use Case Diagram SPK Untuk Pemilihan Jurusan 
Use Case Diagram Pengolahan Data Siswa

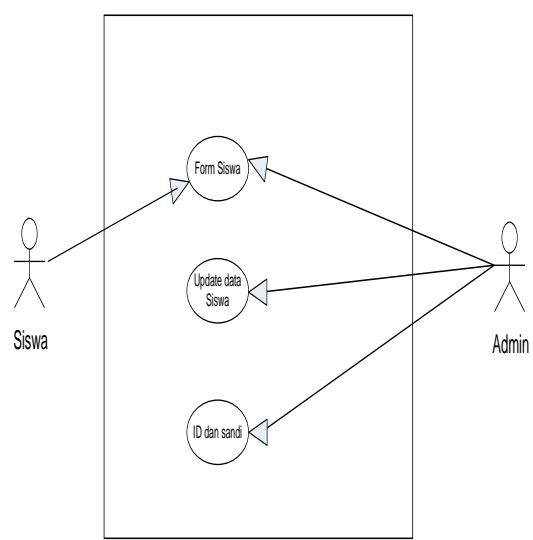

Gambar 8. Use Case Diagram Pengolahan Data Siswa

\section{Use Case Diagram Konsultasi Jurusan}

Use case Konsultasi Jurusan dapat dilihat di gambar di bawah ini:

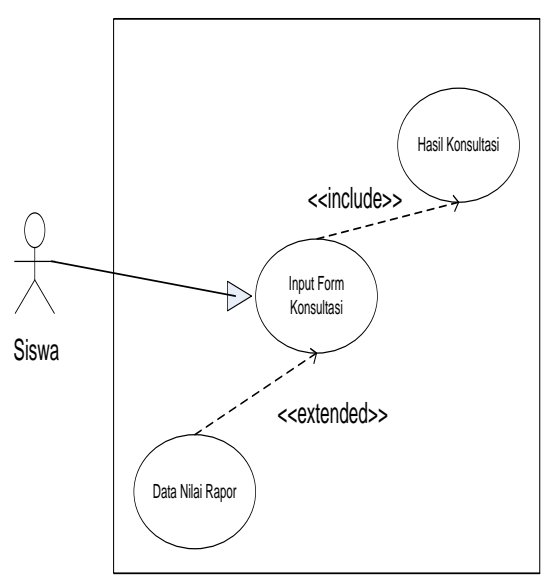

Gambar 9. Use case Konsultasi Jurusan

\section{Use Case Data Jurusan}

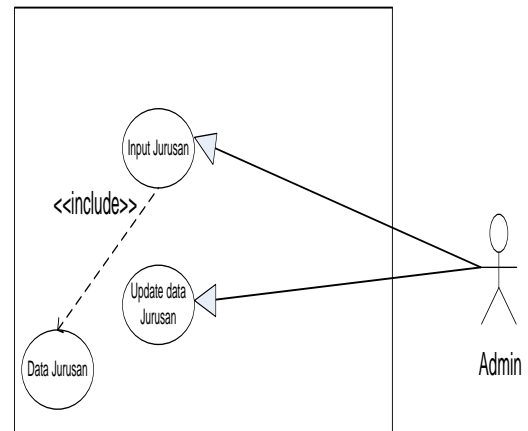

Gambar 10. Use Case Data Jurusan
Use Case Login Admin

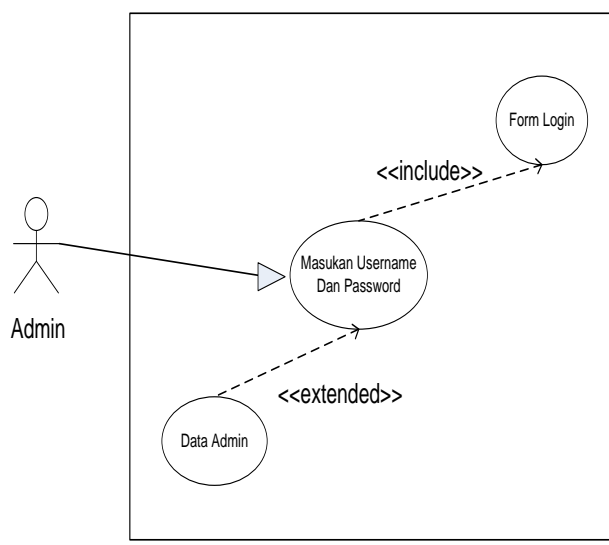

Gambar 11. Use Case Login Admin

\section{Sequence Diagram Login Admin}
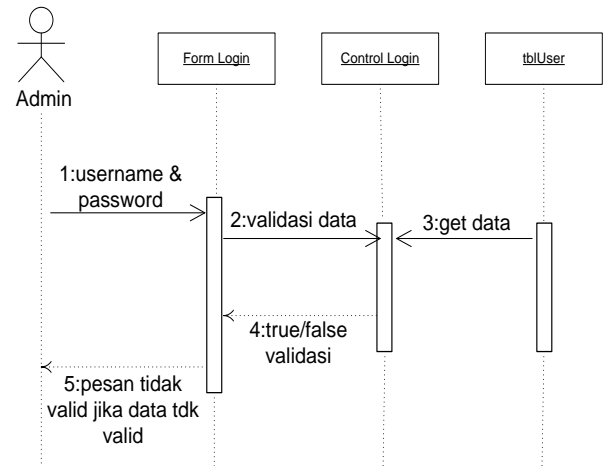

Gambar 12. Sequence Diagram Login

Sequence Diagram Tambah Jurusan

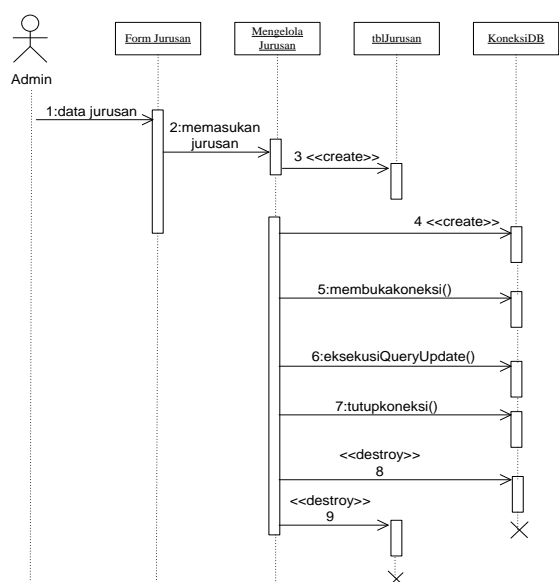

Gambar 13. Sequence Diagram Tambah Jurusan 
Sequence Diagram Tambah Siswa

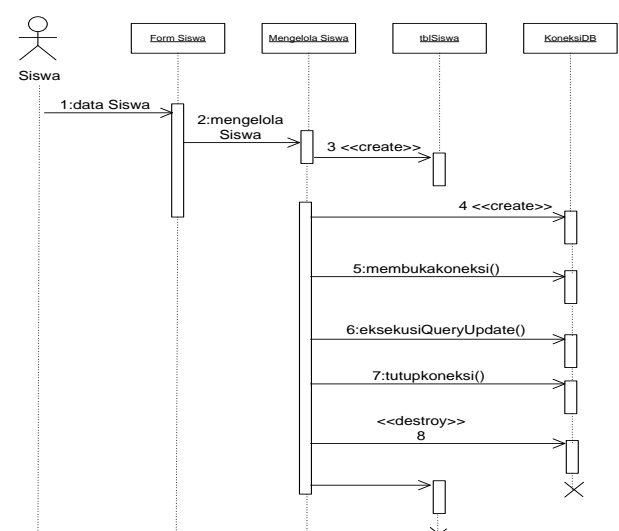

Gambar 14. Sequence Diagram Tambah Siswa

\section{Sequence Diagram tambah konsultasi}

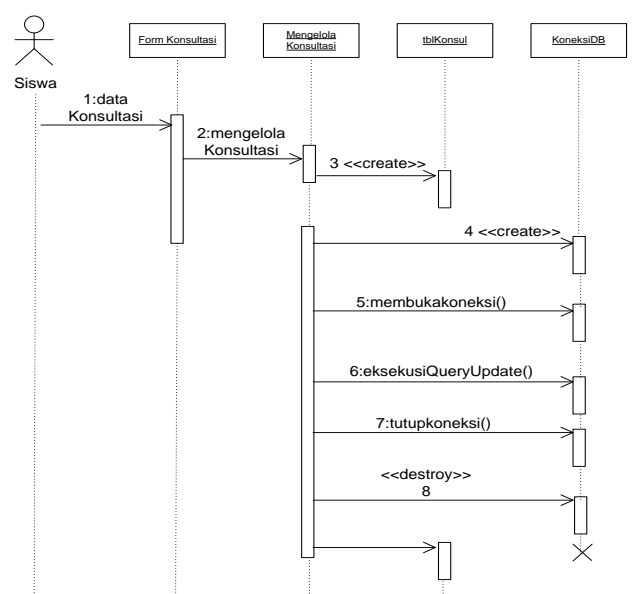

Gambar 15. Sequence Diagram Tambah Konsultasi

\section{Halaman Interface}

1. Halaman Beranda

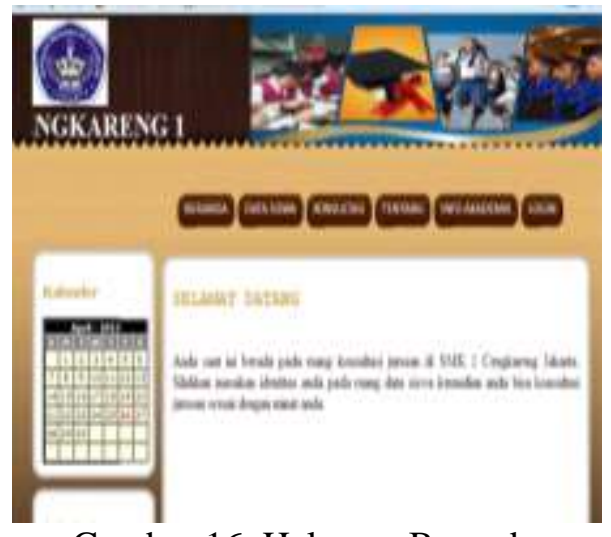

Gambar 16. Halaman Beranda
2. Halaman Form Siswa

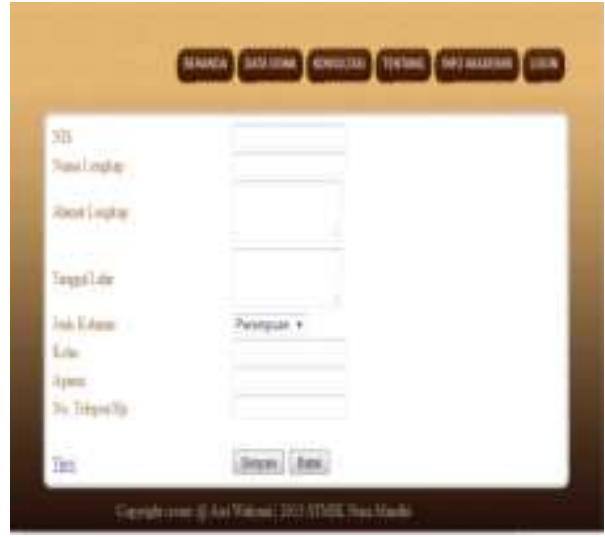

Gambar 17. Halaman Form Siswa

3. Halaman Konsultasi

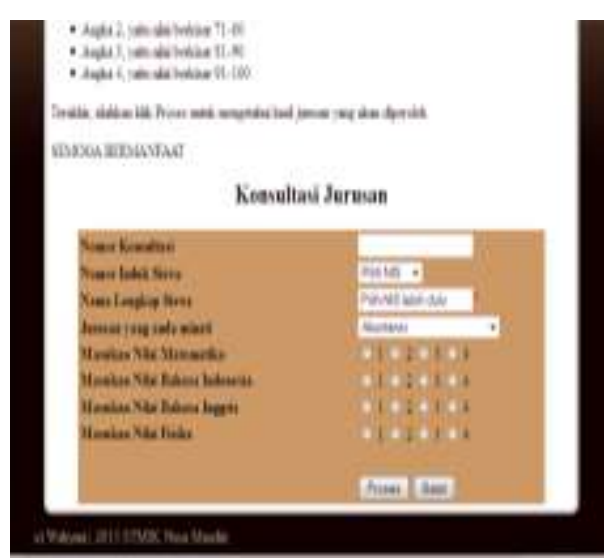

Gambar 18. Halaman Konsultasi

4. Halaman Hasil Konsultasi

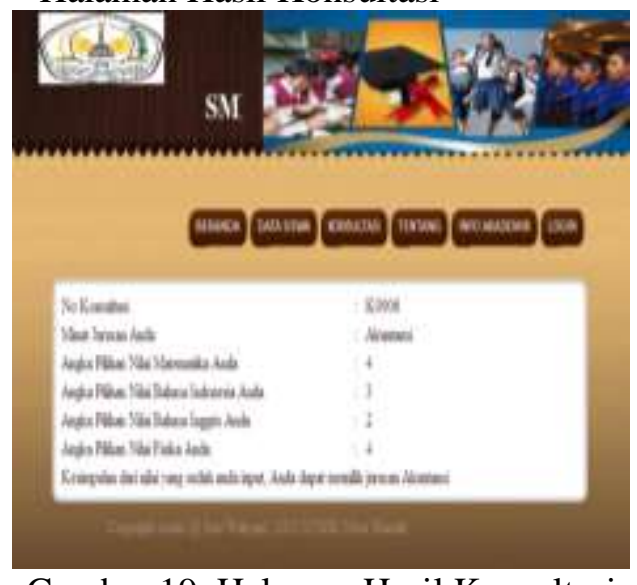

Gambar 19. Halaman Hasil Konsultasi 
5. Halaman Login Admin

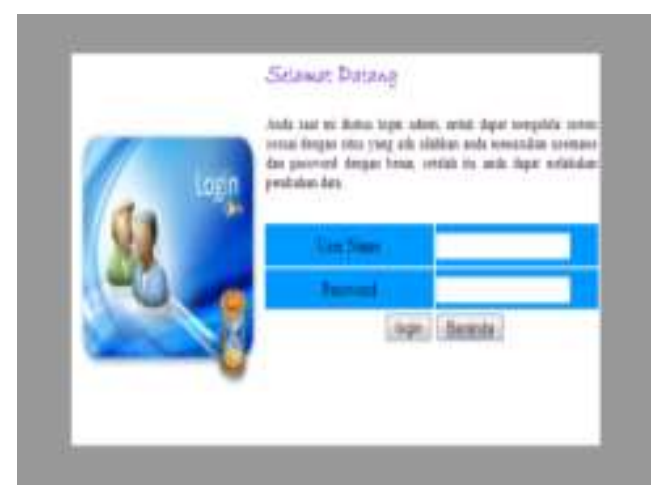

Gambar 20. Halaman Login Admin

\section{KESIMPULAN}

Beberapa hasil yang dapat diperoleh dengan sistem penunjang keputusan untuk pemilihan jurusan ini, yaitu sebagai berikut :

a. Memberikan pelayanan kepada siswa sekolah khususnya siswa SMP (Sekolah Menengah Pertama), dengan menciptakan sebuah sarana konsultasipemilihan jurusan.

b. Membantu dalam melakukan konsulatsi pemilihan jurusan melalui pengolahan komputer sehingga pemilihan yang tidak tepat dapat diperkirakan seminimal mungkin.

c. Memudahkan siswa untuk memilih jurusan sesuai dengan nilai yang diperoleh saat dibangku SMP (Sekolah Menengah Pertama).

d. Pada kondisi tertentu dapat dinilai lebih menghemat waktu karena dapat di akses dimana saja dan kapanpun.

\section{DAFTAR PUSTAKA}

Binanto, Iwan. 2005. Konsep Bahasa Pemrograman. Yogyakarta: Andi.

Darma, Jarot S dan Shenia A. 2009. Buku Pintar Internet. Jakarta : MediaKita.

Fitriyani. 2012. Sistem pendukung keputusan penjurusan SMA menggunakan metode AHP. ISBN 979-26-0255-0. 23 Juni 2012: http://www.publikasi.dinus.ac.id/index.p $\mathrm{hp} / \mathrm{semantik} /$ article/view/214/167. diakses pada tanggal 20 Oktober 2012.
Hermawan, Julius. 2005. Membangun Decision Support System. Yogyakarta:Andi.

Jogiyanto, H.M. 2005. Analisis dan Desain Sistem Informasi, Edisi Kedua. Yogyakarta: ANDI.

Madcoms. 2009. Menguasai XHTML,CSS,PHP dan MySQL melalui Dreamweaver. Yogyakarta: Andi.

Rahma, Fitria dan Dana Indra. 2008. Penerapan Metode Analytic Hierarchy Process Dalam Sistem Penunjang Keputusan Untuk Pemilihan Asuransi. Vol 4 no.2 ISBN 1412-8896.: http://jsi.cs.ui.ac.id/index.php/jsi/article/v iewArticle/253. diakses pada tanggal 20 Oktober 2012.

Ramadhan, Arief. 2005. SQL Server 2000 dan Visual Basic 6. Jakarta: PT. Elex Media Komputindo.

Sanjaya, Ridwan. 2009. Cara Kilat Mempunyai Website Sendiri - Lanjutan. Jakarta: PT. Elex Media Komputindo.

Suhardjo, Wiji dan Bambang Eka P. 2013. Pemanfaatan Local Network dan Program NetOp School Sebagai Media Pembelajaran Interaktif Pada Jurusan Teknik Komputer Jaringan SMK N 1 Klaten. ISSN 2302-5700. IJNS Volume 2 No 3. Juli 2013.

Sutabri, Tata. 2004. Pemograman Terstruktur. Yogyakarta:Andi

Sukamto, Rosa Ariani dan M Shalahuddin. 2011. Modul Pembelajaran Rekayasa Perangkat Lunak (Terstruktur dan Berorientasi Objek). Bandung:Modula.

Trisnawarman, Dedi dan Winny Erlysa. 2007. Sistem Penunjang Keputusan Pemilihan Metode/Alat Kontrasepsi. Vol 9 no.1 Desember2007http://cpanel.petra.ac.id/ej ournal/index.php/tik/viewArticle/16935. diakses pada tanggal 20 Oktober 2012. 